\title{
Encontro com a ontologia dos povos originários: reencontro com as tradições apagadas
}

DOI: : $\underline{\text { https://doi.org/10.5935/1984-9044.20200013 }}$

\section{Kelly Karina Oliveira de Almeida ${ }^{12}$ - Universidade Estadual de Campinas (UNICAMP)}

Resumo: Este trabalho constitui um relato de experiência sobre um encontro e atuação proporcionados pelo estágio eletivo da Residência Multiprofissional de Saúde Mental e Saúde Coletiva da UNICAMP, tendo como recorte a Saúde Mental Indígena em sua interface com as concepções e visões filosóficas que embasam o cuidado com uma adolescente. Utilizamos, para tanto, a filosofia hermenêutica estabelecida por Martin Heidegger, em diálogo com o perspectivismo ameríndio de Eduardo Viveiros de Castro. A partir da análise feita, destacamos a necessidade de reconstruirmos novos pressupostos epistemológicos, um repertório conceitual capaz de transitar, minimamente, em territórios étnicos e culturalmente diferenciados, que sejam capazes de escutar elaborações subjetivas permeadas por sua trajetória cultural, familiar e comunitária. Conclui-se que voltar às coisas mesmas requer esforço de estar mais próximo ao que se vive e como se vive para, a partir daí, construir um encontro que seja significativo e terapêutico para o outro.

PALAVRAS-CHAVE: saúde; saúde mental indígena; fenomenologia.

\section{Encontro com a ontologia dos povos originários: reencontro com as tradições apagadas}

\begin{abstract}
This article aimed to analyze the social interactions between children aged three to four years, in a public early childhood education institution, located in a capital in the southern region of Brazil. We employed Piaget's perspective as theoretical framework to this study. Observations were made with six children, four girls and two boys. We identify in children's interaction with the teacher's alternation between coercion for the adjustment of undesirable behaviors and display of affection and welcoming. We noticed gender difference in the choice of recreational activities and groups formation. This study is an important tool to highlight aspects that can promote healthy child development.
\end{abstract}

${ }^{1}$ Artigo baseado no Trabalho de Conclusão de Curso da autora, sob orientação de Bruno Ferrari Emerich

2 ORCID: https://orcid.org/0000-0001-8025-4112. 


\section{Introdução: sobre experiência, fenomenologia e encontros}

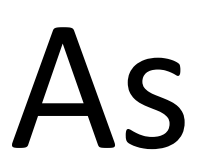

possibilidades de sentidos e de encontros para os seres humanos são imensuráveis. No campo da Saúde Mental acreditamos no potencial dos encontros, do vivido que tece nossa consciência, nas experiências que transformam, como Bondía (2002), em interface com a teoria, para trazer a luz àquilo que de mais originário somos enquanto humanos.

No início e no decorrer do itinerário de formação na residência multiprofissional em saúde mental, pairava uma estranheza e uma sensação de não-lugar que me acompanhava por me interessar pela temática e me aproximar dos processos de saúde-doença-cuidado para os povos originários; talvez de modo parecido com o que esses povos sentem e vivem a chamada sub-humanidade
(Krenak, 2019): indígenas, populações tradicionais, ribeirinhos, pescadores, quilombolas, caboclos, karibós, sertanejos, negros, crackeiros, loucos e moradores de favelas que cobrem nosso país.

Caminhando no tempo chronos e no tempo káiros, compreendi que, embora tais discussões sobre saúde mental para os povos originários estejam distantes e pouco iluminadas pelos campos da saúde, saúde mental, clínica e política, elas se fazem presentes mesmo quando desconsideradas, tal como defendido pelos autores de tradição fenomenológica.

Heidegger formula uma crítica à tradição e história filosófica ocidental que se desenvolveu a partir de Sócrates e Platão, também influenciada por 
Descartes. A crítica de que a metafísica fixa o ser como um ente entre outros se caracteriza pelo esquecimento do ser, e assim vê o próprio ser como objeto. A metafísica também se revela como um pensamento marcado pelo dualismo e expresso sempre por dicotomias (sujeito $x$ objeto; matéria $x$ forma). A era da técnica, como nomeou o autor, que marcou o pensamento ocidental, é essa pretensa dominação e controle por parte do homem sobre as coisas e a natureza, na tentativa de eliminar tudo que é retração ou mistério. Essa postura, elevada a altíssimas potências, transforma o próprio homem em uma das variáveis a serem controladas, ou seja, transforma tudo em objeto a ser usufruído.

Na era da técnica, a verdade (desde Descartes) se baseia na verdade como veracidade (veritas). Essa compreensão de verdade faz-se nítida, por exemplo, no predomínio do cientificismo moderno, no qual tudo é passível de cálculo e previsibilidade. Em Heidegger, a verdade é concebida como a-letheia (palavra de origem grega) que significa desvelamento, não-ocultamento, re- velação. Conceber a verdade como aletheia retoma o mistério que existe em tudo o que se mostra, pois, sempre que algo se revela há também algo que se vela, o que torna qualquer fenômeno irredutível ao pensamento calculista e objetivador.

A fenomenologia assumida por Heidegger teve inspiração em Husserl - o seu fundador formal. Husserl (Feijoo, 2014), em suas investigações, procede de forma a resolver essas dicotomias herdadas das tradições modernas, de interior e exterior, expulsando os conteúdos da consciência e definindo-a como uma relação intencional com o mundo. A consciência está sempre direcionada, ela é intencional, não existe consciência perante o mundo, mas no mundo. A esse movimento, que acontece na relação entre consciência e mundo, nomeou-se intencionalidade (Feijoo, 2014).

Para a fenomenologia “(...) não é partindo de uma posição científica que eu descubro o que vem a ser o mundo, mas localizo o ponto de partida, retornando às coisas-mesmas, sem 
mistura de explicações científicas ou dúvidas metódicas" (Ribeiro Junior, $p$. 64). O retorno às coisas mesmas ou à redução fenomenológica é o exercício de colocar em suspenso todas as afirmações já dadas, concebidas, conhecidas.

\section{Saúde mental, povos originários e a fenomenologia}

Uma política de cuidado em saúde mental para os povos indígenas aconteceu tardiamente no país, sendo que o tema começou a ganhar visibilidade no Brasil somente com a 10 Conferência Nacional de Saúde Mental Indígena, em 2007, promovida pela Fundação Nacional de Saúde (Funasa). "Foi a partir daí que alguns pontos se tornaram centrais como: suicídio, violência, consumo de psicotrópicos, uso de álcool e outras drogas, entre outras" (Batista e Zanello, 2017, p. 633). Contudo, mesmo diante dessas demandas, a produção científica tem sido escassa, principalmente por parte dos profissionais que atuam na saúde e na saúde mental.

Nesse contexto não é só a escassez de produção que nos chama a atenção, mas, sobretudo, a quase inexistência de questionamentos conceituais, bem como as reflexões teóricas pertinentes ao tema da Saúde Mental Indígena. Batista e Zanello (2007) apontam que muitas das produções utilizavam categorias do Manual Diagnóstico e Estatístico de Transtornos Mentais (DSM) e do Código Internacional de Drogas (CID), ou usavam "termos como saúde mental e indígena acriticamente, como termos supostamente descritivos e óbvios" (p.636).

Com perguntas cada vez mais complexas, fomos percorrendo lugares menos óbvios e adentramos em zona desconhecida, ou pouco conhecida, e tem sido preciso lembrar isso constantemente, não por mera apologia, mas, sobretudo, por ética, já que o 
exercício de "perguntar é a única possibilidade de dar voz ao silêncio de um pensar que atende e escuta, que aguarda, abstendo-se de construir soberbos edifícios especulativos"(Borges-Duarte, 2014, p155).

$\mathrm{Na}$ aproximação com o universo dos povos originários, que aconteceu de forma mais intensa na experiência do estágio eletivo proporcionado pela residência multiprofissional em saúde mental da UNICAMP e do DSEI (Distrito Sanitário Especial Indígena), a residente e uma adolescente da etnia Ashaninka se encontraram em terras indígenas localizadas geograficamente no Estado do Acre.

Foi uma longa viagem até a chegada da residente na aldeia, marcadas no corpo pela travessia que se deu primeiro pelo céu, com o voo até o Estado do Acre, ainda na luz do dia. Depois pelas águas do Rio Juruá e Amonia, feita em canoa, sob a luz do luar; e então a passos na terra a caminho da Aldeia, novamente sob o sol. O encontro já acontecia na travessia, antes mesmo da chegada.
Nesse caminhar, o presente trabalho busca esclarecer o sentido próprio da experiência por parte daquele que experiencia. Trata-se de um enfoque metodológico que não tem como objetivo explicar o fenômeno, nesse caso, o encontro, e sim o de mostrá-lo, revelá-lo.

A compreensão de um fenômeno possibilita que acessemos de maneira rigorosa a própria experiência, o que por sua vez amplia os nossos horizontes de entendimento a respeito desse fenômeno, possibilitando que possamos refletir a respeito dele. A abordagem fenomenológica, de acordo com Heidegger, se resume em fazer ver no próprio fenômeno como ele se mostra por si mesmo. Por vezes, pode-se facilmente confundir fazer ciência com um certo número de procedimentos padronizados. Uma compreensão de caráter fenomenológico não se deve fazer valer de quaisquer quadros técnicos ou pré-compreensões que de algum modo possibilitem um entendimento pronto a respeito de um fenômeno, uma vez que 
Não se trata de satisfazer em geral às exigências da tarefa de uma disciplina já-dada, mas, ao oposto: poder-se-ia em todo caso constituir uma disciplina a partir das necessidades de-coisa de um perguntar determinado e do modode-tratamento exigido pelas 'coisas elas mesmas' (Heidegger, 2012, p. 101).

A análise do fenômeno, o ponto de vista da fenomenologia, significa, então, deixar-se mostrar o vivido como fenômeno e constituir um caminho compreensivo pelos seus modos próprios de aparecimento, o que significa tornar seu sentido manifesto. Compreender o sentido de um fenômeno significa compreender o que possibilitou 0 desvelamento do ser de um ente do modo mesmo como ele se desvelou. Trata-se de descobrir qual o caminho percorrido por uma pessoa para compreender uma determinada manifestação do ser, do modo como ele se manifestou.

Heidegger diferencia o modo de ser do ser humano dos outros entes intramundanos e denomina o humano como ser-aí. Ser-aí significa ser o lugar de acontecimento do mundo e da história. Ele afirma que a essência do ser-aí reside em sua existência, e os modos-de-ser possíveis desse ente se dão a partir dele mesmo e somente isso (Heidegger, 2012). O encontro entre a residente e a adolescente Janaína, a partir dessa perspectiva, revela que tal modo de compreender o humano, ou ser-aí, parece ser insuficiente para a compreensão do modo de ser de Janaína. No contexto do encontro, simplesmente não faz sentido, por exemplo, considerar a diferenciação entre entes humanos e não-humanos (intramundanos), como veremos adiante. Contudo, expõe e marca o lugar do acontecimento do encontro para a residente e somente isso.

Na sequência, será narrado um encontro/atendimento com uma adolescente indígena que aconteceu durante o estágio eletivo proporcionado pela residência multiprofissional em saúde mental da UNICAMP. Um dos efeitos provocados pelo estágio eletivo, num primeiro momento, foi a 
experiência de estranheza, que revirava as teorias aprendidas e as práticas realizadas, acompanhada de uma incômoda solidão pulsante que pedia por um lugar. A formação teve a possibilidade de ser ressignificada com a ampliação de tais experiências, de forma que se concluísse compondo com mais diversidade e, assim, um pouco mais integrada.
Tal atendimento se deu a pedido da equipe de saúde indígena que atua no território/aldeia. A partir de um empenho descritivo, em um formato livre, com a utilização do Diário de Campo da residente, buscaremos mostrar o quê e como foi vivido o encontro com o fenômeno da saúde mental indígena. $\mathrm{O}$ relato é da experiência do atendimento da primeira autora, apresentado em primeira pessoa.

\section{O encontro com Janaína}

Janaína me chega primeiro através do relato de sua mãe, enquanto descascava bainhas de feijão no quintal da sua casa e me contava que sua filha não estava bem. Num tom de voz sereno, sem diferentes elevações e expressão facial amigável, relatou que "havia começado alguns meses atrás". Contou-me que Janaína começou a ter "crises", chorava muito, se agitava e, em um desses episódios, disse que queria morrer. Estava tendo visões que mais tarde seu pai veio a descobrir, através de rituais de cura espirituais onde utilizam o Kamarãpi (Ayahuasca), que eram de seus antepassados que apareciam para ela. Contudo, para a mãe, tais visões "não eram normais", e o sofrimento não se justificava. Ela percebia que algo a mais estava acontecendo e não conseguia entender o que era. Esse "algo a mais" causava sofrimento para Janaína, que andava triste e já não queria mais sair mais de casa; já haviam tentado muitas coisas, inclusive deixaram a antiga casa, lugar onde as "crises" começaram, numa tentativa de sair do local onde estavam os espíritos, mas Janaína continuava a se sentir do mesmo modo na casa nova. 
Dirijo-me a Janaína, apresento-me e pergunto se ela quer conversar comigo. Janaína diz que sim e me leva para a cozinha da sua casa, onde, enquanto conversávamos, acariciava um filhote de cotia. Conta que fará 15 anos e é a filha mais velha, tem uma irmã e dois irmãos mais novos. Seu pai é uma das lideranças da comunidade, conduz os rituais espirituais e prepara o Kamarãpi (Ayahuasca), é filho do cacique e da cacica da aldeia; a mãe de Janaína é de outra etnia e professora de português na aldeia. Janaína começa a me falar sobre suas "visões", aponta espontaneamente para a janela, e diz que já teve uma visão ali, entre sua casa de um lado da janela e a mata, do outro lado. Diz que vê algumas pessoas pela casa e às vezes elas falam com ela, que não tem medo dessas pessoas que lhe aparecem e que também não a incomodam. Diz ter também a visão de uma mulher que circula pela sua casa; essa mulher aparece com mais frequência, mas não lembrava no momento de nada que ela tinha lhe falado.

Ela então se volta para mim e me pergunta se algo assim já me aconteceu, se eu já tive algum contato desse tipo. Fico surpresa com a pergunta, respondo a ela que já tive, não do mesmo modo que ela, mas que me importava saber como ela se sentia em relação a essas pessoas. Nesse momento, percebo que a expressão de Janaína muda e solta um sorriso aberto, diz que quer continuar mantendo a relação com o que chama de "outro mundo", mas não quer que seja difícil, e também não queria que seus pais se preocupassem tanto com isso. Conta-me também que não tem muito com quem compartilhar essas experiências, compartilha muitas delas com sua mãe e um pouco com sua prima, da qual gosta muito, mas sente falta mesmo de conversar com o pai. Até pouco tempo atrás ia com ele para algumas atividades, mas conforme foi crescendo parou de acompanhá-lo, e passou a ficar cada vez mais em casa. Seu pai viaja bastante e diz sentir saudades dele, sente sua ausência em casa. A mãe de Janaína é de outra etnia, e às vezes a família viaja para a aldeia da mãe; Janaína gosta muito quando isso acontece. 
Outro fato importante é que na aldeia em que mora não tem o ensino médio. Janaína terminou, no ano passado, o ensino fundamental, e diz sentir muita falta de continuar os estudos; não realiza mais nenhuma atividade diária atualmente, além de cuidar da casa e dos irmãos; se sente responsável por eles e, ao mesmo tempo, sonha em poder continuar os estudos. Diz que gosta muito de ler, leu a maioria dos livros que os pais tinham em casa sobre a história da sua etnia, os segredos da sua comunidade, escritos pelos seus antepassados, mas seus pais a proibiram de continuar as leituras, pois acreditavam que poderia influenciar nas suas "crises" e visões. Ela me mostra um caderno de poesias que escreve e lê um poema sobre o beija-flor. No caderno continha também alguns desenhos padronizados que cria para confeccionar acessórios como pulseiras e colares. Janaína me conta também que não se acha tão bonita, porque não é tão magra ou alta como sua prima; diz que pensa um dia em se casar e sabe que isso vai acontecer, mas tem outras questões no momento. Lembra que acontecerá uma festa na aldeia e me convida para ir com ela. Eu aceito.

Janaína é da etnia Ashaninka. Os indígenas dessa Aldeia falam sua língua originária (Aruak), tendo o português como sua segunda língua. Algumas pessoas têm como a segunda língua o espanhol, pela característica da etnia e da localização da aldeia, que faz fronteira com o Peru e está localizada no Rio Amônia, no município de Marechal Thaumaturgo - Acre. Os Ashaninka possuem parentes e amigos morando em terras peruanas e mantêm esse fluxo constante entre os territórios, não salvo de riscos e perigos.

O deslocamento pelo território é uma das marcas dos Ashaninkas, como nos conta uma moradora: eram "quase nômades", isto é, seus ancestrais tinham uma tradição de migrarem constantemente. Nessas migrações, encontravam um lugar, faziam sua morada, plantavam e partiam para outros lugares, dando chance de a terra se regenerar, além de manterem seu espírito de viajantes. o "quase" em relação ao nômade, nos conta, é pela 
"falta" de outro nome na nossa língua que consiga alcançar o sentido desse peregrinar do seu povo. Com a demarcação das terras indígenas, isso se tornou impossível, pois não podem mais habitar, nem por um curto período, terras que não tenham sido demarcadas para eles. Com isso, começaram a desenvolver técnicas sustentáveis para preservar o território em que vivem. Entre outras coisas, os Ashaninkas desenvolvem um trabalho de repovoamento dos rios e das matas.

Janaína é uma aventureira, uma "quase nômade". Desbravou os caminhos e os segredos dos seus antepassados, que também são os seus, sozinha, através das suas leituras, do contato com os textos sagrados da sua etnia. Os saberes ancestrais, afinal, são medicinais. Quer continuar seus estudos, mas não existe essa possibilidade ainda na sua aldeia. Quer conhecer outros lugares e saberes e pensa, às vezes, em sair da sua aldeia, mas não quer ficar longe da família; gosta quando viajam juntos e encontram parentes e amigos. As viagens periódicas para visitar os parentes fazem parte, afinal, da qualidade de vida de seu povo, que veem na liberdade de andar pela floresta uma das razões da longevidade e da felicidade.

O caminho que Janaína realizou foi de descoberta de uma parte da sua própria história. Para muitos dos povos originários, conhecer e saber sobre a história dos seus antepassados, da sua terra, é imprescindível para um desenvolvimento saudável.

Na analítica existencial de Heidegger, a essência do ser-aí, este ente que todos somos, não é imutável ou determinado, ao contrário, a sua essência está em terde-ser. Para o ter-de-ser do ser-aí, deve se levar em conta o poder-ser. Há uma relação causal entre o ter-de-ser e o poder-ser. Em outras palavras, o ser-aí pode ser quem ele quiser a partir dele mesmo, das suas possibilidades próprias de ser. Desse modo, o poder-ser tem relação direta com a compreensão de ser.

Não há como compreender o ser-aí apartado do seu mundo. Ser-no-mundo é ser o acontecer no mundo. O mundo é um traço do nosso próprio ser, isto é, habitamos nossa interpretação do 
mundo. É justamente nesse sentido que essa noção de existência como ser-aí mostra seu potencial para nossa compreensão. O ser-aí é sempre ser-nomundo; ser-aí nunca é anterior ou posterior ao mundo, ele é cooriginário. Compreensão não equivale a noções cotidianas que correspondem a uma atividade intelectual exercida sobre algo que se apresenta, a fim de melhor "compreendê-lo". A noção de compreensão corresponde à abertura de sentido do ser de um ente para o ser-aí.

Ouvir Janaína foi como me deparar com um mistério. Naquele momento, pensava que nada do que até então havia estudado tanto na psicologia como no campo da saúde mental me prepararam para aquele encontro. Tratava-se de algo completamente inédito ao que a academia me apresentou com os principais autores, em sua maioria de origem europeia, que, apesar de todas as valiosas contribuições, fundamentais para o conhecimento, não me ofereciam suporte naquele momento. Pareceu-me que a sustentação do encontro aconteceu no olhar. No meu e no de Janaína. Seu olhar me parecia triste, um pouco curioso, e sentia que de alguma maneira parecia se sentir confortável comigo. Assim, seu olhar e sua fala repercutiam em mim não como estranheza, mas como uma expansão das possibilidades de experienciar tais vivências e em certa medida assimilá-las.

O mundo de Janaína se mostra, no momento, com restrição das possibilidades de ser a desbravadora do que ainda lhe é desconhecido: nos estudos que gostaria de continuar, nas leituras que gostaria de ter em livros e textos sagrados, nas descobertas e vivências ao acompanhar o pai nas suas atividades, no ser-"quase nômade". Mas, também, em relação ao próprio corpo, quando não se acha tão bonita quanto sua prima. Como não foi possível adentrar com mais cuidado nas relações que as adolescentes Ashaninkas têm com o próprio corpo, penso se tais questões com o corpo se fizeram, de alguma forma, no encontro com o mundo branco.

No dia da festa na aldeia, pude observar que as mulheres Ashaninkas são extremamente vaidosas, principalmente 
as adolescentes. Nas festas se pintam, colocam adornos e enfeites nos cabelos e pela extensão do corpo; e, quando dançam, é um acontecimento de cores e barulhos em movimento.

Janaína passou das caminhadas pela floresta e realização de atividades na sua aldeia, no território, para o limite do espaço da sua casa e, então, seu caminhar e contatos passaram a ser com seus ancestrais e consigo mesma. Durante a fase menstrual, Janaína diz se sentir mais sensível, sentindo, inclusive, muitas dores, fazendo com que suas pernas paralisem e não consiga se mover.

Pergunto-me em que medida o corpo de Janaína também revela a experiência do seu povo, que viveu a aniquilação da possibilidade de andar livremente pela floresta. Lembremos que o projeto colonizador tem como primeiro lugar de ataque o corpo; trata-se de um projeto que encarcera, estupra, mata, tortura, produz pobreza e catequização, que se caracteriza em inúmeras formas de violência. O Ser-aí, como o ser que está no meio do mundo junto aos entes, não se dá fora de uma corporeidade que the é inerente. $\mathrm{O}$ existir, nesse sentido, é corporal, isso quer dizer que o corpo não é aqui um objeto entre outros, tampouco o espírito paira sobre ele como entidade superior.

Segundo o antropólogo Eduardo Viveiros de Castro (1996), o mundo ameríndio desde o norte até o sul tem uma característica ontológica central no que se refere à corporeidade. Para o autor, a existência indígena não poderia ser tipificada como ser-no-mundo, mas como ser-em-ser. Para os indígenas não há separação entre o ser e o universo físico. Ser-em-ser significa que o corpo está entre outros corpos, além de poder transmutar-se nesses corpos. Isso quer dizer que esses corpos não são mais um ente no mundo, não são do mundo, mas são parte do Ser, relacionam-se com o Ser próprio de cada um. A separação entre natureza e cultura ou entre natureza e homem, típica do pensamento ocidental, não tem lugar nesse paradigma.

No universo indígena, todos os corpos (o que inclui animais, vegetais e minerais) possuem mundos análogos ao mundo 
humano. O corpo de um animal ou vegetal não é um corpo objeto, um ente no mundo, mas um outro Ser dotado de linguagem. Nesse sentido, a relação com a Terra exige reciprocidade, pois tudo que tira, tira-se de um Ser. É assim que os Ashaninkas, como Janaína, se relacionam com a terra que habitam e com a que podiam habitar antes da demarcação das terras. O Ser está contido em cada pedaço de Terra, de tal forma que perder a Terra é perder o Ser como um todo. No universo indígena, cada corpo tem sua intencionalidade, seu modo de ser e estar no mundo, cada ser tem um mundo.

A abertura dessa possibilidade de relação com outros corpos, tempos e espaços que cruzam as fronteiras e exploram outras formas de experiência poderia fazer alusão ao entendimento da loucura. Talvez existam poucas coisas mais autoritárias do que dizer para alguém que sua experiência não é legítima, que sua fala não é verdadeira, que este alguém não é quem diz ser, que a terra (ou lugar) não lhe pertence.
Nosso atuar em saúde mental não se direciona a uma escuta que busca maior produtividade humana, nem a adequação de alguém ao mundo. Não tem como fim uma utilidade prática, e sim, a de trazer liberdade, o poder-ser, o movimento de existir. 0 encontro terapêutico consiste no desvelamento e produção de novos sentidos, que somente são possíveis de acordo com a abrangência da abertura ao mundo que nós mesmos somos, pois aquilo que pode dar a nossa abertura de mundo depende do quanto somos livres - do quanto nos apropriamos do nosso próprio ser como liberdade (Magliano e Sá, 2015).

No nosso cotidiano (não indígena) talvez seja um movimento constante o de estar atento ao que a era da técnica nos faz querer exercer e acreditar, isto é, que existe apenas uma direção, apenas um modo de atuar e de viver, ocasionando diversas restrições de possibilidades de ser. Porque ela mesma, a era da técnica, é restrita em liberdade e sentido - tudo busca ser padronizado, mensurado e controlado. 
A fenomenologia existencial foi um lugar de compreensão e um caminho que me ajudou a transpor a experiência em palavras e sentido. $E$, como sentido, compreender que cada situação de viver ou afetação - que nós mesmos somos pode ser um potencial situação de se reconsiderar o nosso próprio modo de ser e atuar, proporcionando uma posição ontológica de transformação.

Janaína parece ter uma relação com os seres e entes de proximidade, mas não tem sido sem angústia que está descobrindo quem é, de onde vem, e quem eram e o que faziam seus ancestrais, seus conhecimentos e sabedorias. Busca encontrar um sentido para o que está vivendo e também um sentido para sua existência. Sentido, aqui, entendido como o lugar em que plantamos nossa inquietude, os lugares possíveis de ser do Ser-aí, que nos abre a possibilidade para descobrir esse lugar e sair do abismo em que a angústia nos coloca. Janaína, enquanto ser-aí, na sua maneira não determinada de ser, na sua peregrinação no mundo, tem a possibilidade de ver e ouvir um novo sentido de ser, possível a cada novo passo. Ao me perguntar se já havia tido uma experiência como a dela, Janaína me ofereceu a possibilidade de me trazer para mim mesma, no estar junto com ela. O que pude conhecer de novo, com os Ashaninkas, seus conhecimentos e sabedorias, despertou em mim também inquietude e angústia, deixando por um momento a ausência de sentido se fazer presente ao pensar e refletir sobre minha atuação enquanto profissional em formação.

Para Boss (1994), a doença é um modo de restrição das possibilidades de ser do seraí; contudo, nem toda restrição necessariamente significa doença ou sofrimento. Restrição no modo de ser são restrições de liberdade de possibilidades de ser que envolvem os existenciais, a saber, espacialidade, corporiedade, temporalidade. $\mathrm{Na}$ psiquiatria de Biswanger, o autor procura reconhecer a enfermidade como um estilo ou modo particular de ser-no-mundo, como variação ou "distorção" da estrutura ontológica de ser-no-mundo. 


\section{As construções históricas sobre saúde mental e as possibilidades de ser para além dos diagnósticos psiquiátricos...}

Como apontado anteriormente, poderíamos fazer alusão ao conceito de Loucura, não para se fazer valer da experiência dos povos originários, mas sobretudo para pensarmos nossa atuação. O autor Pessotti (1994) aponta que a loucura se desenvolveu numa trajetória histórica, que se iniciou na antiguidade até o século XIX e que nem sempre foi sinônimo de doença mental, o que implica dizer que saúde mental é uma construção histórica, cultural e social. O termo saúde, que compõe saúde mental, advém, portanto, da interpretação da loucura como doença, em certo momento histórico, bem como da saúde como ausência de sintomas. O termo mental também é um termo problemático, pois pressupõe, de início, uma possibilidade de separação da mente e do corpo (as ditas dicotomias).

Viveiros de Castro (1996) chama atenção para o fato de que, ao contrário do universo ocidental, que vai se tornando, com o tempo, vazio e pavoroso, o universo indígena é saturado de seres e não de entes. O autor aponta que, para o xamã, o acesso ao espírito não se relaciona com a alteração de uma consciência, mas faz parte de uma ontologia que não cinde o mundo entre sujeito e objeto, ao gosto do ocidente, e também não prioriza ontologicamente o pensamento humano sobre o kosmos. Tal apontamento recai sobre a crítica à expressão "saúde mental indígena", obrigando-nos a aceitar que seja errôneo utilizá-la para trazer à luz vivências que dizem respeito aos povos originários.

Na psiquiatria transcultural - uma das ramificações da antropologia médica - é possível encontrar discussões e estudos sobre a comparação do sofrimento mental em diferentes culturas. A ênfase nessa abordagem é dada principalmente à aflição (illness) mais do que à doença (disease) (Batista, 2014). Os autores da psiquiatria transcultural afirmam que muitas 
ENCONTRO COM A ONTOLOGIA DOS POVOS ORIGINÁRIOS: REENCONTRO COM AS TRADIÇÕES APAGADAS

culturas reconhecem comportamentos fora do padrão esperado como um tipo de problema específico, mas, ao mesmo tempo, nem sempre o interpretam como doença (Kirmayer, 1994).

Podemos afirmar que muito se discute sobre a atuação da medicina e o uso de medicamentos para a saúde mental, mas muito pouco (ainda) sobre a atuação dos profissionais; podemos apontar um exemplo disso com o transbordamento do Manual do DSM (Manual Diagnóstico e Estatístico de Transtornos Mentais) para outras culturas. Tal transbordamento tem propiciado o que Alarcon (citado por Batista, 2014) chamou de nova forma de colonização cultural americana.

Martinez-Hernáez (2000) acredita que um dos problemas enfrentados pela psiquiatria em outros contextos culturais diz respeito, principalmente, ao tipo de diagnóstico realizado por ela: o diagnóstico que nada mais é senão uma listagem descritiva de sintomas (utilizando-se do DSM). Além disso, também constitui problema o fato de ela não considerar tais sintomas como um conjunto de significados enraizados em um dado contexto sociocultural e como esses sintomas são expressivos das realidades simbólicas do sofrimento.

O Manual do DSM, a partir de sua terceira edição, lançada em 1980, tinha e ainda mantém, segundo Neto e Calazans (2012), ao menos três pretensões: "ser um manual científico; por ser científico, ser universal; por ser universal, colocar fim às inúmeras discussões teóricas que estão presentes na história da psicopatologia” (p. 9). Segundo Julien (2009), o universal é uma busca pelo Absoluto de um princípio, sem exceções, por um categórico universal. É da ordem do prescritivo, da razão, um dever-ser; consiste em uma herança do pensamento grego, não apenas como conceito, mas como modo de ver a realidade, e se caracteriza por estar voltado para o Um, Uni-versus, se distanciando do Di-versus e contrastando, portanto, com o individual e o singular. Um dos pontos altos dos paradigmas da psiquiatria, em todos os seus momentos, diz respeito justamente à noção de adoecimento como fenômeno individual, cuja etiologia remete a causas "internas", com total ou parcial responsabilidade do adoecido, não se levando em consideração fatores como o social, econômico, cultural. 
Essa concepção de diagnóstico, que supostamente inclui um cuidado, se assemelha, em muito, aos objetivos da era da técnica, distanciando-se, consideravelmente, da atuação que acreditamos ser terapêutica e efetiva no campo da saúde mental. Distancia-se ainda mais dos povos originários, para os quais, na grande maioria das sociedades indígenas brasileiras, o indivíduo é um ser coletivo em essência (Krenak, 2019).

Faz-se necessário reconstruirmos, com base em novos pressupostos epistemológicos, um repertório conceitual capaz de transitar em territórios étnicos e culturalmente diferenciados, sem um caráter violento e colonizador. Ainda estamos longe de vencer todos os desafios que fazem parte de um diálogo efetivo com questões de saúde mental nos diversos contextos culturais, principalmente entre as populações indígenas brasileiras.

O des-velar de outras possibilidades de modos-de-ser mostrou-se também como um aprender para a pesquisadora residente. Não foram apenas des-velados modos-de-ser possíveis dos povos originários, mas sobretudo possibilitou a abertura de sentidos que cada troca pode proporcionar para a construção de um caminho de cuidado, através da experiência do encontro, em que se pôde trazer à luz conhecimentos e sabedorias invisibilizados de povos que estão muito mais próximos do que apenas geograficamente

\section{Referências}

Acçolini, G. \& Silva, J, J. (2015). Rituais de passagem bororo: conservação, fabricação e destruição do corpo. Apresentação de trabalho/comunicação. 
ENCONTRO COM A ONTOLOGIA DOS POVOS ORIGINÁRIOS: REENCONTRO COM AS TRADIÇÕES APAGADAS

Araujo, L, F, S, Dolina, J, V.,Petean, E., Musquim, C, A., Bellato, R., \& Lucietto, G, C. (2013). Diário de pesquisa e suas potencialidades na pesquisa qualitativa em saúde. Rev. Bras. Pesq. Saúde, Vitória (15)3: 53-61, jul-set.

Batista, M, Q. (2010).Saúde Mental Indígena. Um desafio interdisciplinar. Monografia de Conclusão de Curso em Psicologia no Centro Universitário de Brasília.

Batista, M, Q. (2014). Saúde mental e populações indígenas. desconstruindo a psicopatologia e problematizando categorias. Dissertação de mestrado apresentada ao Instituto de Psicologia da Universidade de Brasília.

Batista, M, Q. \& Zanello, V. (2017). "Saúde Mental" "Indígena" : do que estamos falando e a partir de onde? Coleção psicologia clínica e cultura - UnB. v. 3. Universidade de Brasília.

Borges-Duarte, I. (2014). Arte e técnica em Heidegger. Lisboa: Ed. Documenta. Bondía, J, L. (2002). Notas sobre a experiência e o saber da experiência. Tradução: João Geraldi - Unicamp.

Dussel, E. (2011). Filosofía de la Libertación. México: Fondo de Cultura Económica. Evangelista, P. (2016) Algumas reflexões acerca da psicoterapia daseinsanalítica com pacientes psiquiátricos. Psicologia Revista, v. 25, p. 59-75.

Feijoo, A. M. L. C. (2011). A existência para além do sujeito. 1. ed. Rio de Janeiro: Viaverita.

Heidegger, M. (2012). Ser e tempo. Petrópolis, RJ.:Vozes, 6.ed. 
ENCONTRO COM A ONTOLOGIA DOS POVOS ORIGINÁRIOS: REENCONTRO COM AS TRADIÇÕES APAGADAS

ISA - Instituto Socioambiental. Povos Indígenas no Brasil.

Krenak, A. (2019). Ideias para adiar o fim do mundo. São Paulo: Companhia das letras.

Lessin, L. (2011). Nos rastros de Yakuruna: a partida de Pawa e a póssustentabilidade Ashaninka. Tese (doutorado em Ciências Sociais) Universidade Estadual Paulista, Faculdade de Filosofia e Ciências.

Magliano, F. R. \& Sá, R. N. (2015). Reflexões Heideggerianas sobre técnica, liberdade e práticas psicológicas clínicas. Arquivos Brasileiros de Psicologia. 67 (2),

Oury, J. (1991). Itinerários de formação. Revue Pratique, (1), 42-50. Tradução: Jairo I. Goldberg.

Ribeiro Jr, J. (2003). Introdução à fenomenologia. Campinas: Edicamp.

Santos, G, A, O. (2018). Terapia Existencial da Libertação - Ensaios introdutórios. Editora Fi.

Viveiros de Castro, E. (1996). Os pronomes cosmológicos e o perspectivismo ameríndio. Revista Mana, Rio de Janeiro, 2 (2),

Povos Indígenas do Brasil 2001/2005. Disponivel em: https://pib.socioambiental.org/files/file/PIB_institucional/No_Brasil_todo_mun do_\%C 3\%A9_\%C3\%ADndio.pdf

Recebido em: 21/08/2020 Aprovado em: 15/12/2020 